\title{
The inexact and separate philosophy of economics: an interview with Daniel Hausman
}

DANiEl M. HAuSMAN (Chicago, 1947) is currently Herbert A. Simon professor in the Department of Philosophy at the University of Wisconsin-Madison. He attended Harvard College, where in 1969 he received a BA in English history and literature. After completing an MA in teaching at New York University while teaching intermediate school, he spent two years studying philosophy at Gonville and Caius College at Cambridge University (UK) before earning his $\mathrm{PhD}$ in philosophy in 1978 at Columbia University.

Professor Hausman has taught at the University of Maryland at College Park, Carnegie Mellon University, and since 1988 at the University of Wisconsin-Madison. Most of his research has focused on methodological, metaphysical, and ethical issues at the boundaries between economics and philosophy, and he has been prominent in the development of philosophy of economics as a separate discipline. In collaboration with Michael McPherson, he founded the journal Economics and Philosophy and edited it for its first ten years. He also edited The philosophy of economics: an anthology (3rd edition, 2007). His most important books are Capital, profits, and prices: an essay in the philosophy of economics (1981), The inexact and separate science of economics (1992), Causal asymmetries (1998), and Economic analysis, moral philosophy, and public policy (co-authored with Michael McPherson, 2006). His latest book, Preference, value, choice, and welfare will be published in 2011 by Cambridge University Press. He is currently working on a book on the measurement of health.

In this interview, Professor Hausman offers some reflections on his approach to the philosophy of economics, and on various topics central to recent methodological discussions, such as the role of abstraction, idealizations, scientific representation, and causality in economics.

EJPE'S NoTE: This interview was conducted by Luis Mireles-Flores, PhD candidate at the Erasmus Institute for Philosophy and Economics (EIPE), Erasmus University Rotterdam, and co-editor of the Erasmus Journal for Philosophy and Economics. 
EJPE: Professor Hausman, you did a BA in English history and literature and an MA in teaching before moving to do philosophy. How did you come to write a PhD thesis in philosophy of economics?

DANIEL HAUSMAN: Well, originally I was doing biochemistry. My own intellectual strengths in high school and early college were really much more in the sciences and mathematics. But I started university in 1965, when the United States was undergoing lots of student turmoil-that and a combination of rebellion against my parents and being part of a movement committed to the view that the United States needed transformation prevented me from seeing myself simply as a scientist. I wanted to be doing something that seemed more relevant to people and their experiences.

English history and literature actually wound up pushing me in the direction of political philosophy. As an undergraduate I did a thesis on Shakespeare's play Troilus and Cressida, which is very much about the breakdown of the political order of the traditional late-medieval-world picture that Shakespeare was working in. And by the time I graduated, it was clear to me that I did not want to be doing English literature. I had naïve views that a revolution was coming, and I did not think I should immediately go on to graduate school. I did not know quite what to do. Initially I thought about doing some teaching as a way of avoiding getting drafted and going into the army, but I actually got a medical deferment so I was free of the army.

It still seemed that by doing some teaching I would be learning more about other parts of society, and also making contacts in preparation for the revolution. So I joined an MA in teaching program mainly for the possibility of teaching without already being certified as a teacher. Half of the program at NYU was basically teaching. I taught in the South Bronx, which at the time-and I think it is still the case-was an extremely poor area of the city. I visited some of the students' homes and, though the apartments were decent, the buildings were just horrible. You would walk through garbage two or three feet thick in the lobbies before climbing out of it on the stairways. The buildings were really quite frightening places. There was a heroin drop right in front of the school where at eleven in the morning the dealers would gather and portion out the heroin. The policeman who was usually posted by the school would leave just before eleven and come back after the drug dealers had left. 
This was only for a year. I was not a very successful teacher. I was teaching 5 th, 6 th, 7 th, and 8 th graders who had many, many learning difficulties and psychological problems. I was unwilling or unable to be very authoritarian, and with almost no exceptions the only teachers who succeeded in the school were quite brutal to the kids in order to keep order. I did not have enough confidence that being brutal would do the students any good, so often my classes were semi-disastrous. I ran back to graduate school after this unsuccessful but in certain ways rewarding interlude.

I applied to Cambridge to do an affiliated degree in what at that time was called "moral sciences" rather than philosophy-there is now an undergraduate philosophy degree at Cambridge. I did a second BA precisely because I had not had much philosophy as an undergraduate at Harvard. I had done a few courses, including one with John Rawls, which was quite a special experience, and several political theory courses with Michael Walzer, who was a fantastic teacher. I also went to Cambridge for purely personal reasons: my girlfriend at the time was planning on going to England to work on English history. However there was a postal strike and she could not get her applications in, so I ended up going to England without her. That is a good example of my abilities to plan for the future.

So, I got my undergraduate training in philosophy at Cambridge. I still had no inkling that I would end up doing philosophy of science or philosophy of economics. At that time I was writing papers in history of philosophy and moral philosophy, and when I was at Columbia as a graduate student I still envisioned myself as mainly doing moral philosophy. When I started working on a dissertation, it was on the moral consequences of role theory as it was conceived of in sociology. I did not make much progress. Then I happened to sit in on a series of lectures by John Eatwell-now Lord Eatwell in England-on the Cambridge controversy. He is a wonderful lecturer. Though I wound up disagreeing with quite a lot of what he had to say when I wrote my dissertation, his account of the Cambridge controversy was very exciting. I was particularly struck with the contrast between his account of the nature of argumentation in the Cambridge controversy and what I had learned in studying philosophy of science.

This was a period when many philosophers of science were doing empirical work. Not empirical work studying nature, but empirical work studying the way scientists were studying nature. At the time, there had 
been very little of this done with respect to economics. The first work of this kind with respect to economics that I had learnt of was Alexander Rosenberg's Microeconomic laws: a philosophical analysis (1976). But I only came across this book when I was already working on my dissertation project.

Listening to Eatwell's lectures, I thought, gee, this particular controversy is methodologically very peculiar, very interesting, and this would be a rewarding topic for applied philosophy of science. It was never my view that philosophy of science had all the answers, which could then be mechanically applied to economics. I believed philosophers of science understood some things well, but I thought philosophy of science was imperfect. By triangulating between what I would learn about the economics and what I knew from the philosophy of science, I thought I could contribute to some extent to both enterprises. And that is the twisting story of how I ended up doing philosophy of economics.

\section{Did you also have some specific training in economics?}

I knew a little bit of economics at that point. I had taken one semester as an undergraduate of a year long survey course which seemed to me so stupid that it really was not worth my time. I found it very easy and of little interest. The first semester was on microeconomics and it was really at a baby level. It did not even expect calculus, but if you knew some calculus basically all you had to do was differentiate a couple of functions and you got an 'A' on all the tests. So the little bit of economics I knew at the beginning did not get me very far. Because of my political interests, I also sat in on a course on Marxian economics taught by a wonderful elderly immigrant scholar, Alexander Ehrlich.

When I started doing the dissertation I had to learn capital theory, some serious microeconomics, general equilibrium theory, and of course I studied the capital controversy, and Piero Sraffa's work which lies behind the Cambridge-England side of the Cambridge controversy. At one time I think I knew capital theory quite well. I also had a pretty good grasp of microeconomics and general equilibrium theory, and I studied several past accounts of capital theory, such as the works of Knut Wicksell and Frank Knight.

With respect to macroeconomics, I read J. M. Keynes, but that was not really knowing macro the way a student who has worked through a modern textbook would know macro. I figured out I needed to know 
what IS-LM analysis was, so I looked at that, but basically I did not really know macroeconomics. And related to capital theory, I studied a bit of growth theory, but it was a spotty kind of knowledge of economics. I did virtually no econometrics, and I am still not a great statistician by any means. I sat in on some other economics courses, but I did not formally take any later courses. So I am not a particularly well trained economist. I am largely self-taught.

The work of John Stuart Mill is an obvious influence on your writings. Were there any other particular texts or authors in the history of economics that had an important influence on your approach to philosophy of economics?

Apart from Ehrlich's course on Marxian economics, I might have sat in on a course on the history of economic thought, I am not certain. But I did definitely read the classic texts. Although I turned the pages very quickly when I got to all the discussion on the prices of corn, I read the whole of Adam Smith's Wealth of nations, and I definitely read David Ricardo and Nassau Senior.

I did not read J. S. Mill's Principles of political economy until later, but I read his methodological texts, and in writing my dissertation I was pretty careful about reading things in the history of methodology itself, so I read Mill, John Cairnes, John Neville Keynes, Lionel Robbins, and some of the methodological work of Frank Knight. I got reasonably well versed in the history of economic methodology, including the voluminous literature on Milton Friedman's "The methodology of positive economics" (1953). I also read some of Stanley Jevons, and I definitely read John Bates Clark, Eugen Böhm-Bawerk, and people like that, because of the capital controversy. So I certainly had more than a smattering of the history of economics.

You mention that you felt you should study the history of economic methodology, but this was at a time when there was no such thing as a clearly differentiated discipline called 'methodology of economics'. So how did you know what to read?

I do not know exactly how I knew what to read on the methodology of economics. It probably was just a matter of following the references in one author to another author. It would have been obvious enough to read people like Smith, Ricardo, and Mill, or the really important figures in the history of economics, but I do not know how I knew to 
read John Neville Keynes, for example. Perhaps it was Milton Friedman's reference to Neville Keynes in his essay on the methodology of positive economics. Somehow other readings put me onto it.

Already as an undergraduate student I had read some John Stuart Mill in political philosophy courses. I definitely read his On liberty, and knew of his Utilitarianism. I am sure I read his Autobiography-I do not know exactly why-and I remember thinking: wow, here is this really substantial philosopher who is also a really substantial economist. This is somebody who I have to look at.

The inexact and separate science of economics (1992) is to a great extent a criticism and elaboration of J. S. Mill's methodology of economics. Has anything changed in your thinking since the publication of your book?

In a couple of articles (Hausman 1995; and 2001), I explored a problem with Mill's views that I did not clarify in the book. Mill is very emphatic on the difficulties of learning about economic relationships by means of what he calls the "method a posteriori" or the "method of direct experience". He gives the example of trying to investigate by simply looking at data whether a tariff increase would decrease national wealth. We cannot learn the effects of tariffs by aggregate comparisons, because there are so many other causal factors apart from tariff rates that differ among nations or across time in an individual country. He is quite emphatic on this point, but I think he exaggerates the problem. In any case he is also emphatic about the need for verification, and if we really cannot learn anything from looking at comparisons of countries, then we also cannot verify the deduction that comes out of the theory that tariffs would in fact diminish national wealth. Mill is to some extent aware of this. Thus he held that if we can get an agreement between these two kinds of "evidence"-he uses that term-namely the deductive derivation from fundamental theory and what we observe, then such agreement will suffice to justify claims to knowledge.

He seems at this point to have forgotten his view about inductive Proof, with a capital 'P', that shows up in book 3 of his A system of logic, and in any case his view is questionable. It seems that if someone is going to be serious about learning about the economy, either using direct or indirect inductive methods, it has got to be the case that they have empirical tools to gather useful aggregate economic data that provide serious direct evidence about regularities such as those 
concerning the effects of tariffs. I think in fact that this is not an impossible thing, but Mill comes close to saying that it is impossible. There are some real tensions here, and I think that a successful philosophy of economics has to spell out and make room for more substantial uses of what Mill called methods of direct experience. Indeed, as problematic and flawed as different econometric methods are, I think that we can learn some things from them. But I do not think Mill teaches us much about how to do that.

More generally, I do not believe Mill solved the problems of economic methodology, but understanding his views greatly helps us to understand the problems. His views compare pretty well with the views of lots of contemporary thinkers.

In a recent seminar at EIPE, you referred to Mill's method a priori and quoted his claim that no economist "was ever so absurd" as to really believe humans are exclusively motivated by the pursuit of wealth. Economists make "an entire abstraction of every other human passion or motive" but only as part of their method. Could you clarify your position on the role of abstraction in economics?

For Mill, as I read Mill, abstraction is not the view that economists should create fictional artificial unrealistic models where they simply consider how one causal factor would operate all by itself. It is rather that economists start out knowing-and I think it is problematic whether economists do know this-that there is one causal factor which is of predominant importance with respect to economic phenomena. But I do not think he has an answer to the question of how do you know such a thing, John Stuart? That the pursuit of wealth is the predominant cause is what he grew up knowing. His father probably drummed it into him by age six.

Mill denies that his method is just a hypothetical method, yet it is to some extent hypothetical. Although economists are abstracting and simplifying, they know that they are abstracting and simplifying from the minor causes, from the lesser causes, not from the greater causes. Knowing this does not imply that economists might not sometimes get things radically wrong, because those minor causes are not completely trivial, and they can add up and falsify predictions that focus on only the effects of the pursuit of wealth. Nevertheless, on average the other causal factors would be weaker, and they may cancel one another out. So although economics is a science of tendencies, these are tendencies 
that economists ought to be seeing in the data. If they are not seeing them in the data, then they have failed to verify their models, and they need to go back and perhaps question whether they have captured the major causes, whether some of the things left out really are relatively minor and could legitimately be left out, or whether they have botched their model and drawn false inferences. But ultimately Mill still is really an empiricist. He insisted that these are inductive methods, and he is serious about that, as I read him.

Is that what has led you more recently to explore the behavioral assumptions of economics, the fact that traditional approaches are obscure about where these behavioral assumptions come from in the first place?

I do not think that came so much from reading Mill. It is rather that, if one looks at fundamental mainstream economic theory itself, one should have less confidence than Mill had that introspection and everyday experience justify being confident that the theory has picked out not only significant generalizations but the most important causal factors governing economic behavior. I think one really needs to raise the question of to what extent the kinds of abstractions that economists are making are useful, especially given the experimental work which directly challenges many of the assumptions of mainstream economic theory and shows not just that people do not always live up to the axioms, but that there is systematic divergence from the axioms.

If one is serious about being an empiricist about science (there are all kinds of empiricism-I am not a behaviorist or something like that, but I am an empiricist about science), then the only excuses for using such an idealized theory would be either that there is no alternative or that it really is doing valuable work for us. But there are alternatives, at least in some domains, and in various applications it is not obvious that the theory is doing valuable work. Many economists may disagree with me here, but if one takes economic theory seriously and recognizes the complexity of many of the possible circumstances in which it will be applied, the standard implications economists would like to draw from theory cannot be drawn.

Consider for example the implication of the theory of the firm that an increase in the minimum wage will increase unemployment among unskilled workers. Well, if it is a big enough increase, then (other things being equal) I am convinced. If the U.S.A. Congress were to set the 
minimum wage at $\$ 30$ an hour, there would be lots more unemployment among unskilled workers. I believe what the theory apparently implies thus far. But if we are thinking about the actual policy alternatives, which involve relatively small increases in the minimum wage, it is not easy to derive any implications about the effects on employment, and there is typically no way from the theory to get any sense of what the magnitudes are. And the magnitude really matters. If you wound up with 0.1 percent increase in unemployment, that is going to be a small social cost; while if you wound up with a 10 percent increase in unemployment, that is going to be serious-and the theory itself is not going to really help you answer those questions.

Idealized mainstream economic theory provides a powerful fundamental framework, and I do not claim that people should not learn it. But the notion that it should have a monopoly on the way economists model economic phenomena seems to me unjustifiable. This is stated a little bit differently, but it is very similar to the conclusions I draw in The inexact and separate science of economics (1992).

What is your current view on modeling and scientific representation in economics?

I am inclined to think that there is a very simple and useful characterization of modeling in economic theory, though not of modeling in econometrics, which is very different. Basically I think it is useful to regard modeling as a kind of conceptual exploration, a way of using mathematical tools to ask: what if?

In mainstream economics, models are narrowly constrained by the requirement that they be consistent with a set of basic axioms. Conformity with these axioms (rationality, self-interest, profit maximization, and so on) makes something part of mainstream economics. Although particular assumptions can be relaxed, most will hold. Mainstream models not only agree on their basic generalizations, they also share certain stylized descriptions of the agents and their environment.

So economic models resemble what Max Weber called "ideal types". Models depict fictionalized simplified worlds which are governed by certain kinds of generalizations. Specific models will contain additional specific assumptions, but at their core are the basic principles of mainstream economics and standard stylized descriptions of what the 
circumstances are. With the elements in place, economists then reach into their mathematical toolkit and see what kinds of things result.

There are a variety of reasons to engage in constructing models such as these and investigating their mathematical implications. One reason is that economists might think that their stylized descriptions of the circumstances actually are in some sense a reasonable approximation to the actual circumstances, that the generalizations are actually true, and that economists can then use these models to predict and explain features of the actual circumstances. Economists can also use a model (as Max Weber often suggests with respect to ideal types) as a diagnostic tool to identify ways in which reality differs from the model. There would be no point in doing that, unless economists thought that there is something significant about the model. I can talk about a number of ways in which the moon differs from a great big piece of green cheese, but there would be no point in doing that. Nobody cares how it differs from a piece of green cheese, because nobody thought it was a piece of green cheese beforehand.

Since there is such general commitment to the basic structure of neoclassical modeling, conflicts between what a mainstream model predicts and what is observed are of interest. If economists find that a model is inapplicable to some actual circumstance, that finding could in principle challenge the scope or validity of the explanatory generalizations built into the model. It will likely lead mainstream economists to look harder at their stylized descriptions of the circumstances, and it may help them to realize that they are missing something significantly different or additional about the real world. In this way current theoretical commitments can provide stepping stones toward building a better theory. Having constructed a simple model and examined its flaws, economists can construct more complicated models and, using more complicated mathematics, derive implications that are of explanatory and predictive use.

What sort of entities can be used in these three ways, namely to apply mainstream economics, to study the ways in which reality differs from what theory implies, and to develop more complex and subtle applications of theory? In my book (1992), I suggest that one should regard models in economic theories as either predicates or as definitions of predicates. (These two views are obviously different, but they are easily intertranslatable.) Of course to apply models one needs more than definitions or predicates, but that is a different 
question from what constitutes a model. This account is extremely simple, but I am not taken with any of the more elaborate alternative accounts in the current literature on modeling and scientific representation, where one finds almost everything called "a model".

But in your book (Hausman 1992), you also present a much more specific account of scientific representation in which theoretical hypotheses are what connect economic models to reality-very close to Ronald Giere's view of scientific representation. Could you elaborate on this account?

Yes, but that account is extremely simple too. If the model is simply a definition of a predicate or a predicate or a depiction of a hypothetical world, then it does not make any claims that are true or false of the actual world. To make substantive claims, one has to make some claim about the relationship between reality and the model. Such claims are what I call theoretical hypotheses. I follow Ronald Giere in using this fancy terminology. Suppose, for example, that you propose a simple model of rationality: someone is rational* if and only if his or her preferences are complete and transitive and determine what is chosen. This makes no claims about actual people. Given this definition, one can offer a variety of theoretical hypotheses. One could say that all people are rational*. Or one could say that when the moon is full, Americans are not rational*. The model provides a conceptual resource that the person concerned about reality can put to use by formulating theoretical hypotheses.

Economists have to be willing to assert some theoretical hypothesis: that the world is just like some model, that it is not like this model, or that it is like a model in this way and not like it in this other way. But until economists assert some theoretical hypothesis they have not said anything about any actual economic circumstances. The model itself says nothing about reality. One can treat models as trivially true (as a definition), or as a predicate rather than a proposition and thus not the kind of thing that could be true or false. The assessment of the model is a question of how useful the model is. It is not whether the model is true or false.

What about cases like Schelling's segregation models or von Thünen's isolated state where there seems to be no intended theoretical hypothesis about a resemblance relation between the model and 
reality, but rather they seem to be intended to represent some existing mechanism so as to show its workings in a particular fictional setting?

I have read about von Thünen's model, but I have not actually read von Thünen, so I would rather not comment on him. With respect to Schelling's (1969) model, I see it as addressing a theoretical question: is it possible to get racial segregation without the population being overwhelmingly racist? Can you get racial segregation where in fact you have relatively few racists? And he then gives you a story showing how that is possible. This use of the model is quite different from employing it to describe what happens, because I do not think that Schelling is committed to the claim that this model resembles reality in any significant way. Nor is he committed to the claim that the mechanism whereby we get segregation in his model is in fact the mechanism that leads to segregation within the actual world.

He is not using the model as a contrast to the actual world either. He is not saying, if you look at the model and see the ways that it does not fit the actual world that is what will lead us to notice important other things about the world. The model is instead being used to answer a how-possible question; and it is very powerful in this sense-it is lovely! Although Schelling's use of the model is different from the way in which economists might use the model of rationality* that I sketched above, his model matches my conception perfectly naturally. He defines an artificial system, an artificial world, and is not making any claims about this being in itself true or false. He investigates its mathematical properties, and shows how a little bit of "bias" leads to very strict segregation. That is really interesting, but what it shows us is that something that we might not have thought of as possible is in fact entirely possible.

This idea of showing "that something that we might not have thought of as possible is in fact entirely possible" brings to mind David Ricardo's model of comparative advantage. But that also seems a quite different type of modeling from that employed in Schelling's segregation model.

What Ricardo shows in his model is that if country A has comparative advantage over country $B$ with respect to the production of $a$ commodity then it can trade with B, even if B has an absolute advantage 
with respect to the production of all commodities, and that that trade will be mutually advantageous. Unlike Schelling he is not just demonstrating a possibility (though he is doing that too). He is prepared to assert the theoretical hypothesis that the mechanism he identifies operates in reality-that the predicate he defines is (to some degree of approximation) satisfied by actual countries. He is inclined to make the claim that in its significant details the actual world is like his model-despite the fact that with respect to many details it is utterly different, since there are many more than two commodities, and all sorts of other possibly relevant circumstances. If, like Ricardo, you are prepared to take the leap and say that those differences really do not matter (it is not that they do not matter at all, but that they really do not make that much difference), then the actual world is like the model's world, and then you can derive the conclusion that trade will be mutually advantageous in the real world.

The model itself does not show you that result. You have to have this additional risky hypothesis that the differences between the model and the actual world are relatively minor, and if you can take the model as defining a comparative advantage world, you are then prepared to say that the actual world is a comparative advantage world. That would be a way of fitting it into the language that I used in The inexact and separate science of economics (1992).

The comparison between the two models is very interesting-I never thought of it-because Ricardo's partakes to some extent of the same kind of thing that Schelling's does, but there is nothing in Schelling's model which purports to show that, regardless of the institutional arrangements, whenever there are certain preferences for proximity you always get segregation, and that this is the one and only mechanism that will get you there. So Schelling is much more just saying: look, here is something that you did not think was possible before I gave you the model. Ricardo is doing that too, but he is also saying: and this is going to be the inevitable result of comparative advantages regardless of absolute advantages in any real world circumstances which in the relevant respects resemble my model.

Recurrent notions in your work since the 1980s have been: causal factors, causal judgments, causal mechanisms, causal explanation, and causal priority, and you wrote a whole book devoted to causal 


\section{asymmetries (Hausman 1998). How do you understand the relation between causation and economics?}

In my very first book, on capital theory (Hausman 1981), I ran into a slew of difficult causal issues in trying to think through Piero Sraffa's work. So already at the very beginning, my work in philosophy of economics pushed me to think about causation. It did not push me hard enough, because I would have done better to incorporate much more causal thinking in The inexact and separate science of economics (1992) and in my other work before that. In particular, rather than attempting to construe generalizations such as "People prefer more commodities to fewer" as inexact laws that contain in their antecedents vague ceteris paribus conditions, I would now argue that these generalizations be understood as stating causal tendencies and that what I construed as ceteris paribus conditions be for the most part understood as specifying the domain in which the tendency operates.

The work I have done on causation-and I have done quite a lot of work on causation-really came out of reading in philosophy of economics. Herbert Simon's views have had a huge influence, for instance, on my interest in exploring the issue of the direction of causation (e.g., Hausman 1984; 1998). If you look at Simon's essay "Causal order and identifiability" (1953), or at Guy Orcutt's "Toward partial redirection of econometrics" (1952), it is causal order that is important. They do not use much philosophical jargon, but what is really crucial about causal relations as opposed to mere correlations is that you can control events by intervening on their causes. Mere temporal ordering is not enough, because one effect of a common cause may precede another. In both Orcutt's story and in Simon's more theoretically elaborated account, what is crucial to causation is not temporal order but the direction of influence and possible control. There are many similarities with more elaborate contemporary philosophical accounts such as those defended by James Woodward (2003).

The remarkable developments in the causal modeling literature to which computer scientists, statisticians, philosophers, and economists have all contributed have also helped to shape my views on causation. The issues are, however, too lengthy and technical for us to pursue them much further here. 
Some of your most recent work is on the analysis of preferences. As a closing comment, could you give us an outline of this project?

I have just completed a book, Preference, value, choice, and welfare that should be out from Cambridge University Press near the end of 2011 or the beginning of 2012. The book is about preferences, mainly as they are and ought to be understood in economics, but I also have some things to say about preferences in everyday language and action, in psychology, and in philosophical reflection on action and morality. In this book I clarify the notion of preferences that economists rely on and to a considerable extent defend the way economists use the notion of preference. But I am also critical of misconceptions concerning preferences that many economists and other social scientists hold.

In the economist's picture of choice and welfare, agents rank alternatives in terms of everything that matters to them. Preferences are, in this sense, total comparative evaluations. Among the available alternatives, the agent then chooses as far up the preference ranking as the constraints-such as prices or availability-allow. How far up the agent is able to go determines how well off the agent is.

In positive economics, this preference ranking governs people's choices. In normative economics, the objective is to move people up their preference rankings. The principles of positive economics are mostly generalizations concerning preferences and what they imply for choice. Normative economics is concerned with how best to satisfy preferences. Preferences lie at the core of mainstream economic theory, and my book aims to clarify what preferences are and how they figure in economic theory and practice.

\section{REFERENCES}

Friedman, Milton. 1953. The methodology of positive economics. In Essays in positive economics, Milton Friedman. Chicago: University of Chicago Press, 3-43.

Hausman, Daniel M. 1981. Capital, profits, and prices: an essay in the philosophy of economics. New York: Columbia University Press.

Hausman, Daniel M. 1984. Causal Priority. Noûs, 18 (2): 261-279.

Hausman, Daniel M. 1992. The inexact and separate science of economics. Cambridge: Cambridge University Press

Hausman, Daniel M. 1995. The composition of economic causes. The Monist, 78 (3): 295-307.

Hausman, Daniel M. 1998. Causal asymmetries. Cambridge: Cambridge University Press. 
Hausman, Daniel M. 2001. Tendencies, laws, and the composition of economic causes. In The economic world view: studies in the ontology of economics, ed. Uskali Mäki. Cambridge: Cambridge University Press, 293-307.

Hausman, Daniel M. 2007 [1984]. The philosophy of economics: an anthology. Cambridge: Cambridge University Press.

Hausman, Daniel M., and Michael S. McPherson. 2006. Economic analysis, moral philosophy, and public policy. Cambridge: Cambridge University Press.

Orcutt, Guy H. 1952. Toward partial redirection of econometrics. The Review of Economics and Statistics, 34 (3): 195-213.

Rosenberg, Alexander. 1976. Microeconomic laws: a philosophical analysis. Pittsburgh: University of Pittsburgh Press.

Schelling, Thomas C. 1969. Models of segregation. The American Economic Review, 59 (2): 488-493.

Woodward, James. 2003. Making things happen: a theory of causal explanation. Oxford: Oxford University Press.

Daniel Hausman's Website: <http://philosophy.wisc.edu/hausman/> 